$\mathrm{AB} 0554$ SLEEP QUALITY IN PATIENTS WITH PSORIATIC ARTHRITIS

P. Benzin ${ }^{1}$, Z. R. Stisen ${ }^{1}$, M. Skougaard ${ }^{1}$, T. Schjødt Jørgensen ${ }^{1}$, R. L. Hansen ${ }^{1}$, L. M. Perez-Chada ${ }^{2}$, M. Mogensen ${ }^{3}$, J. F. Merola ${ }^{2}$, L. E. Kristensen ${ }^{1}{ }^{1}$ Parker Institute, Clinical Research Unit, Frederiksberg, Denmark; ${ }^{2}$ Brigham And Women's Hospital, Department of Dermatology and Department of Medicine, Division of Rheumatology, Boston, United States of America; ${ }^{3}$ Bispebjerg and Frederiksberg Hospital, Department of Dermatology, København, Denmark

Background: Psoriatic arthritis (PsA) is a chronic immune-mediated inflammatory disease. It has a heterogeneous clinical presentation with main features being joint swelling and pain, skin and nail psoriasis, enthesitis, and dactylitis. Self-reported outcomes such as quality of sleep and fatigue are often neglected topics although having great impact on patients' everyday lives.

Objectives: The primary objective was to analyze the prevalence of PsA patients suffering from poor quality of sleep, defined by Pittsburgh Sleep Quality Index (PSQI) score $\geq 5$, and to study the association between being a good or poor sleeper and clinical- and patient-reported outcomes.

Secondary, the effects on outcomes after initiation of treatment.

Methods: Patient characteristics, disease activity and self-reported outcomes were obtained from the PIPA cohort. To evaluate the primary objective, a cross-sectional analysis was conducted including PSQI score at baseline and corresponding data. Patients were divided into two groups, defined as good or poor sleepers (Table 1).

Data from initiation of treatment (baseline) and 4 months follow-up were included when assessing the effect of treatment. Transition of good and poor sleepers from baseline to 4 months follow-up was depicted by a chi-squared test.

A crosstab analysis was performed with baseline PSQI and whether they had widespread pain to investigate a possible link, additionally a Mann-Whitney $\mathrm{U}$ test.

Results: From January 2018-November 2020 a total of 109 patients were included. The prevalence of PsA patients suffering from poor quality of sleep at baseline were $66.1 \%$ whereas the remaining $33.9 \%$ were deemed good sleepers. There was no statistically significant difference in patient demographics when comparing good and poor sleepers at baseline. There was a statistically significant difference in patient-reported outcomes such as Visual Analogue Scale (VAS) pain, VAS global, Health Assessment Questionnaire (HAQ) score and Disease Activity Score (DAS28-CRP), with poor sleepers scoring higher.

57 patients had complete data at 4 months follow-up. At baseline $71.9 \%$ of them were classified as poor sleepers (Figure 1). A chi-squared test presented the transition at 4 months follow-up. $47.4 \%$ of the patients were now classified as poor sleepers.

While 27 poor sleepers became good sleepers, 13 good sleepers became poor sleepers, with data being statistically significant ( $p$ 0.001).

The crosstab analysis exposed 75 patients without widespread pain (mean $7.13 \pm 3.79$ ) and 31 patients with widespread pain (mean 9.52 \pm 4.93 ).

Baseline PSQI and whether the patients had widespread pain was statistically significant ( $p$ 0.018).

Conclusion: Overall, PsA patients with poor quality of sleep have higher levels in terms of self-reported pain and disease activity.

The amount of good sleepers after 4 months increased, but there was a negative transition of patients going from good to poor sleepers. This could indicate that more factors are important for quality of sleep, e.g. sociopsychological aspects like anxiety, depression, ability to work.

Table 1. Patient characteristics

\begin{tabular}{|c|c|c|c|c|c|c|}
\hline & \multirow[t]{2}{*}{$\begin{array}{c}\text { Total } \\
n=109\end{array}$} & \multicolumn{2}{|c|}{$\begin{array}{c}\text { Good sleepers } \\
\text { PSQI } \leq 5 \\
n=37\end{array}$} & \multicolumn{2}{|l|}{$\begin{array}{c}\text { Poor sleepers } \\
\text { PSQI > 5 } \\
n=72\end{array}$} & \multirow[b]{2}{*}{$\mathrm{p}$} \\
\hline & & \multicolumn{3}{|c|}{$n$} & $\mathrm{n}$ & \\
\hline Female, n (\%) & $65(59.4 \%)$ & $19(51.4 \%)$ & 37 & $46(63.9 \%)$ & 72 & 0.206 \\
\hline Age, yrs & $53.9(45.4-62.25)$ & $60.4(45.5-65.2)$ & 37 & $51.5(44.7-59.95)$ & 72 & 0.144 \\
\hline $\begin{array}{l}\text { Disease duration, } \\
\text { yrs }\end{array}$ & $3.86(1.0-11.0)$ & $4.5(1.04-11.06)$ & 34 & $2.91(1.0-10.75)$ & 68 & 0.352 \\
\hline csDMARD, n (\%) & $71(65.1 \%)$ & $26(70.2 \%)$ & 37 & $45(62.5 \%)$ & 72 & 0.420 \\
\hline bDMARD, n (\%) & $70(64.2 \%)$ & $24(64.8 \%)$ & 37 & $46(63.9 \%)$ & 72 & 0.920 \\
\hline $\begin{array}{l}\text { Patient pain } \\
\text { assessment }\end{array}$ & $50.0(21.0-74.5)$ & $27.0(9.0-60.5)$ & 37 & $63.5(32.25-78.0)$ & 72 & $<0.001$ \\
\hline 0-100 mm VAS & & & & & & \\
\hline $\begin{array}{l}\text { Patient global } \\
\text { assessment }\end{array}$ & $61.0(27.5-78.5)$ & $35.0(17.5-59.0)$ & 37 & $69.5(50.0-85.75)$ & 72 & $<0.001$ \\
\hline $0-100 \mathrm{~mm}$ VAS & & & & & & \\
\hline PsAID fatigue & $6.0(3.0-8.0)$ & $4.0(2.5-7.0)$ & 37 & $6.5(4.0-8.0)$ & 72 & 0.488 \\
\hline HAQ score, 0-3 & $0.75(0.38-1.25)$ & $0.38(0.25-0.81)$ & 37 & $0.88(0.63-1.38)$ & 72 & $<0.001$ \\
\hline PASI & $1.7(0.0-9.75)$ & $2.0(0.0-7.3)$ & 35 & $1.2(0.0-11.5)$ & 65 & 0.940 \\
\hline DAS28-CRP & $3.77(3.02-4.58)$ & $3.44(2.65-3.94)$ & 37 & $4.07(3.28-4.93)$ & 72 & 0.001 \\
\hline
\end{tabular}

Figure 1. Quality of sleep
Baseline

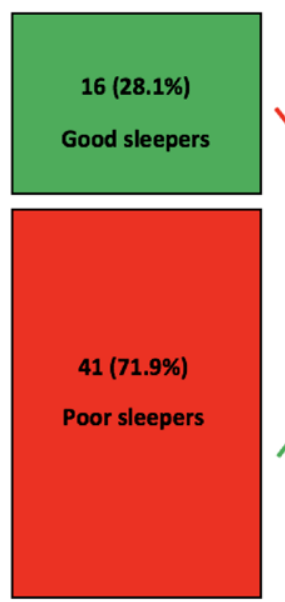

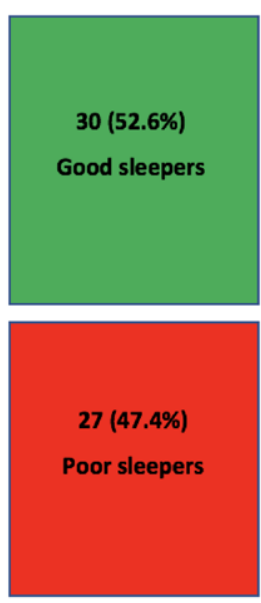

4 months follow-up

Disclosure of Interests: Peter Benzin: None declared., Zara Rebecca Stisen: None declared., Marie Skougaard: None declared., Tanja Schjødt Jørgensen Speakers bureau: Received consulting fees and/or speaking fees from AbbVie, Pfizer, Roche, Novartis, UCB, Biogen and Eli Lilly, Consultant of: Received consulting fees and/or speaking fees from AbbVie, Pfizer, Roche, Novartis, UCB, Biogen and Eli Lilly, Rebekka L. Hansen: None declared., Lourdes M. PerezChada: None declared., Mette Mogensen: None declared., Joseph F. Merola Consultant of: Consultant and/or investigator for Merck, Bristol-Myers Squibb, AbbVie, Dermavant, Eli Lilly, Novartis, Janssen, UCB, Sanofi, Regeneron, Arena, Sun Pharma, Biogen, Pfizer, EMD Sorono, Avotres and Leo Pharma., Lars Erik Kristensen Speakers bureau: Received fees for speaking and consultancy from Pfizer, AbbVie, Amgen, UCB, Gilead, Biogen, BMS, MSD, Novartis, Eli Lilly, and Janssen pharmaceuticals., Consultant of: Received fees for speaking and consultancy from Pfizer, AbbVie, Amgen, UCB, Gilead, Biogen, BMS, MSD, Novartis, Eli Lilly, and Janssen pharmaceuticals. DOI: 10.1136/annrheumdis-2021-eular.2294

\section{AB0555 IMPACT OF ADALIMUMAB VERSUS NON-BIOLOGIC THERAPY ON CLINICAL AND PATIENT-REPORTED OUTCOMES IN PSORIATIC ARTHRITIS OVER 24 MONTHS - RESULTS OF THE COMPLETE-PSA CANADIAN OBSERVATIONAL STUDY}

M. Khraishi ${ }^{1}$, S. Silverberg ${ }^{2}$, Y. Setty ${ }^{3}$, M. C. Laliberté ${ }^{4}$, L. Bessette ${ }^{5} .{ }^{1}$ Memorial University of Newfoundland, Memorial University of Newfoundland, St. John's, Canada; ${ }^{2}$ Etobicoke General Hospital, Etobicoke General Hospital, Toronto, Canada; ${ }^{3}$ Grey Bruce Health Services, Grey Bruce Health Services, Owen Sound, Canada; ${ }^{4} \mathrm{AbbVie}$ Corporation, Montreal, AbbVie Corporation, Montreal, Montreal, Canada; ${ }^{5}$ Laval University, Centre Hospitalier de I'Université Laval, Laval University, Centre Hospitalier de l'Université Laval, Quebec City, Canada

Background: COMPLETE-PsA was a Canadian observational study of biologic-naïve adults with active psoriatic arthritis (PsA) treated with adalimumab (ADA) or conventional systemic disease-modifying anti-rheumatic drugs (csDMARDs) after switch from a previous conventional therapy.

Objectives: To compare the impact of ADA vs csDMARDs on clinical and patient-reported outcomes due to PsA over 24 months.

Methods: Eligible patients were biologic naïve adults with active PsA who required change in their treatment due to inadequate response or non-tolerance, as per treating physician judgement. Patients were enrolled between July/2011 and December/2017 and followed for a maximum 24 months. Treatment was as per routine care. Outcome measures included tender/swollen joint count (TJC/ $\mathrm{SJC}$ ), morning stiffness ( $\mathrm{min} /$ day), patient's global assessment of disease activity (PtGA) and pain (both $100 \mathrm{~mm}$ VAS), quality of life (DLQI), and functional disability (HAQ-DI). Outcome changes over time were evaluated using multivariable models adjusting for baseline measures. Achievement of modified minimal disease activity [mMDA, $5 / 7$ of: TJC and SJC $\leq 1$ each, psoriasis BSA $\leq 3 \%$, pain $\leq 15$ (VAS, mm), PtGA $\leq 20, \mathrm{HAQ}-\mathrm{DI} \leq 0.5$, and no enthesitis], and presence of enthesitis and dactylitis, were assessed descriptively. Analyses were conducted in the intent-to-treat population.

Results: A total of 277 ADA and 148 csDMARD-treated patients were included in the analysis. At baseline, $61.7 \%$ of ADA and $81.1 \%$ of csDMARD patients reported concomitant methotrexate. Compared to the csDMARD group, ADA-treated 
patients demonstrated significantly $(p<0.05)$ greater baseline disease severity with respect to mean (SD) joint count [TJC: 8.9 (6.2) vs. 7.4 (6.6); SJC: 7.4 (5.0) vs. 5.9 (4.6)], morning stiffness [83.5 (98.2) vs. 61.8 (77.4) min/day], PtGA [56.1 (24.1) vs. $45.1(24.7) \mathrm{mm}]$, pain [58.5 (24.3) vs. $50.1(24.0) \mathrm{mm}]$, DLQI scores [6.1 (6.9) vs. 4.3 (5.3)] and HAQ-DI [1.1 (0.6) vs. $0.8(0.6)]$. The rate of baseline mMDA was slightly lower for ADA patients (4.3\% vs. $7.4 \% ; p=0.178)$. Baseline prevalence of enthesitis was comparable (ADA: $28.4 \%$ vs. csDMARD: $23.4 \%$ $\mathrm{p}=0.276$ ), while dactylitis was significantly more prevalent for csDMARD patients (26.2\% vs. $36.3 \%$; $p=0.031$ )

Overall effect of treatment group, over 24 months, significantly $(p<0.05)$ favored the ADA vs. csDMARD-treated patients for TJC [estimate $(95 \% \mathrm{Cl}):-2.4(-3.4$, -1.4)] SJC [-1.8 (-2.5, -1.2)], PtGA [-3.7 $(-9.3,1.9)]$, DLQI [-1.5 (-2.5, -0.5)], and HAQ-DI $[-0.1(-0.2,0.0)]$ (Figure 1). There was no significant difference for morning stiffness and pain.

At month 24 , statistically comparable $(p>0.05)$ baseline-adjusted values (the least square means: LSM) were observed for ADA- vs. csDMARD-treated patients for TJC [LSM $(95 \% \mathrm{Cl}): 1.8(1.2,2.4)$ vs. $3.0(2.1,3.8)]$, SJC $[1.2(0.8,1.7)$ vs. $2.1(1.5,2.7)]$, morning stiffness $[32.4(19.1,45.6)$ vs. $29.9(11.1,48.6) \mathrm{min} /$ day], PtGA [31.6 $(28.1,35.2)$ vs. $36.9(31.8,41.9) \mathrm{mm}$ ], pain [35.3 $(31.5,39.0)$ vs. $38.4(33.1,43.7) \mathrm{mm}$ ], DLQI [2.9 $(2.2,3.6)$ vs. $2.9(2.0,3.8)]$, and HAQ-DI [0.7 $(0.6,0.8)$ vs. $0.9(0.8,1.0)]$.

Achievement of mMDA at month 24 was reported by $34.1 \%$ and $34.9 \%$ of ADA- and csDMARD-treated patients, respectively $(p=0.892)$. Rates of dactylitis $(10.6 \%$ vs. $10.0 \%)$ and enthesitis $(9.6 \%$ vs. $14.4 \%)$ were comparable in the ADA vs. csDMARDs groups respectively.

Conclusion: The results of this real-world Canadian study indicate a physician selection bias for treatment with ADA for PsA patients with more severe disease burden, indicated by greater baseline disease activity and PROs. ADA-treated patients experienced a greater treatment effect over 24 months compared to csDMARD-treated patients. However, despite the greater treatment effect of ADA, residual disease burden in the two groups was comparable at 24 months.

Acknowledgements: The authors wish to acknowledge JSS Medical Research for their contribution to the statistical analysis, medical writing, and editorial support during the preparation of this abstract. AbbVie provided funding to JSS Medical Research for this work.

Disclosure of Interests: Majed Khraishi Speakers bureau: Speaker for AbbVie, Consultant of: Consultant for AbbVie, Grant/research support from: Principal Investigator for AbbVie, Samuel Silverberg Consultant of: Consultant for AbbVie, Janssen, and Pfizer, Yatish Setty Consultant of: Advisory Board meetings with AbbVie and Janssen, Marie-Claude Laliberté Employee of: Employee of AbbVie, Louis Bessette Speakers bureau: Speaker for Amgen, BMS, Janssen, UCB, AbbVie, Pfizer, Merck, Celgene, Lilly, Novartis, Gilead, Sandoz, Fresenius Kabi, Consultant of: Consultant for Amgen, BMS, Janssen, UCB, AbbVie, Pfizer, Celgene, Lilly, Novartis, Gilead, Sandoz, Samsung Bioepis, Fresenius Kabi, Grant/research support from: Investigator for Amgen, BMS, Janssen, UCB, AbbVie, Pfizer, Merck, Celgene, Sanofi, Lilly, Novartis, Gilead.

DOI: 10.1136/annrheumdis-2021-eular.2589

\section{AB0556 COMPARING EFFICACY OF GUSELKUMAB VERSUS USTEKINUMAB IN PATIENTS WITH PSORIASIS ARTHRITIS: AN ADJUSTED COMPARISON USING INDIVIDUAL PATIENT DATA FROM DISCOVER 1\&2 AND PSUMMIT TRIALS}

J. Diels ${ }^{1}$, P. Thilakarathne ${ }^{2}$, A. Schubert ${ }^{3}$, F. Hassan $^{4}$, S. Peterson ${ }^{5}$, W. Noel'. ' Janssen Pharmaceutica, HEMAR Department, Beerse, Belgium; 2 JanssenCilag Ltd, HEMAR Department, Beerse, Belgium; ' Janssen-Cilag Poland, HEMAR Department, Warsaw, Poland; ${ }^{4}$ Janssen-Cilag Ltd, HEMAR Department, High Wycombe, United Kingdom; ${ }^{5}$ Janssen Global Services, LLC, Janssen Immunology Global Commercial Strategy Organization, Raritan, NJ, United States of America

Background: Guselkumab is an anti-interleukin (IL)-23 monoclonal antibody recently approved for a treatment of Psoriasis arthritis (PsA). In two large Phase III trials of patients with PSA (DISCOVER -1 \& -2) guselkumab has shown to be superior versus placebo. In this indication no direct comparison is available between guselkumab and ustekinumab, a monoclonal antibody targeting IL-12 and IL-23. Indirect comparisons based on relative treatment effects versus a common comparator (placebo) only allow for analyses up to week 24 due to cross-over to active arms in available PsA trials.

Objectives: To compare indirectly joint and skin efficacy of guselkumab versus ustekinumab up to week 52, using pooled patient-level trial data from DISCOVER $1 \& 2$ and PSUMMIT 1\&2, adjusting for cross-trial population differences.
Methods: Patient level data, including baseline characteristics and outcome data on American College of Rheumatology (ACR) response, Psoriasis Area Severity Index (PASI) response from the guselkumab arms of DISCOVER \& -2 were pooled with the data from the ustekinumab trials PSUMMIT -1\& 2. Analyses were performed for bio-naïve and bio-experienced populations separately. Differences in patient characteristics across trial populations were adjusted for using multivariate logistic regression, including: gender, age body mass index, previous TNF use, disease duration, PASI level, number of swollen and tender joints. This method of indirect comparisons allows for analysis of comparative efficacy beyond controlled induction period and odds ratios' resulting from this model were translated into predicted response rates for ustekinumab, assuming same patient population, as enrolled in the guselkumab trial arms.

Results: Majority of baseline characteristics for patients on guselkumab (100mg q8w; 100mg q4w) were comparable to patients on ustekinumab $45 / 90 \mathrm{mg}$, in both in bio-naïve and bio-experienced group of patients. The probability of reaching a ACR 20 in both the bio-naïve \& bio-experienced population was significantly higher for guselkumab vs ustekinumab at weeks 52 for both dosing regimens of guselkumab (bio-naïve ACR 20: q8w OR=1.88 [1.28;2.76]) $q 4 \mathrm{w}(\mathrm{OR}=1.92$ [1.29;2.86]; bio experienced ACR20 q8w OR=2.72[1.17;6.31] $q 4 \mathrm{w}$ OR=4.77 [1.95;11.63]). Similarly guselkumab was superior over ustekinumab on PASI 90 outcome at week 52 in both bio-naïve \& bio-experienced patients with $B S A \geq 3 \%$ at baseline (bio-naïve: q8w OR=2.59 [1.68;3.99]), q4w $\mathrm{OR}=3.19$ [2.03;5.00], and bio-experienced $q 8 \mathrm{w}$ OR=3.96[1.39,11.27], q4w OR=13.10[4.18,41.04]). Figure 1 represents unadjusted pooled DISCOVER $1 \& 2$ trial results and estimated proportions of ustekinumab treated patient group achieving ACR 20 in bio-naïve patient group up to week 52 using the method described above.

Conclusion: An adjusted comparison using patient level data from pivotal Phase III studies demonstrates both dosages of guselkumab to be significantly more effective versus ustekinumab in both skin and joint outcomes in both bio-naïve \& bio experienced patients up to week 52 .

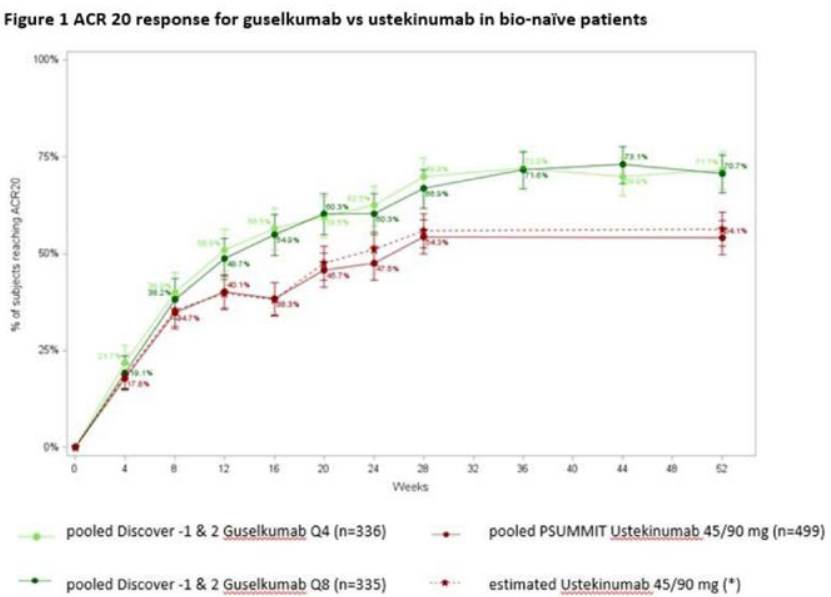

Disclosure of Interests: Joris Diels Shareholder of: Janssen, Employee of: Janssen, Pushpike Thilakarathne Employee of: Janssen, Agata Schubert Shareholder of: Janssen, Employee of: Janssen, Fareen Hassan Shareholder of: Janssen, Employee of: Janssen, Steve Peterson Shareholder of: Janssen, Employee of: Janssen, Wim Noel Shareholder of: Janssen, Employee of: Janssen.

DOI: 10.1136/annrheumdis-2021-eular.2595

\section{$\mathrm{AB} 0557$ \\ ACHIEVING TREATMENT TARGETS IN PSORIATIC ARTHRITIS WITH APREMILAST IN CANADIAN PRACTICE: REAL WORLD RESULTS FROM APPRAISE}

V. Chandran ${ }^{1}$, L. Bessette ${ }^{2}$, C. Thorne ${ }^{3}$, M. Sheriff ${ }^{4}$, P. Rahman ${ }^{5}$, D.

D. Gladman ${ }^{1}$, S. Anwar ${ }^{6}$, J. Jelley ${ }^{7}$, A. J. Gaudreau ${ }^{7}$, M. Chohan ${ }^{7}$, J.

S. Sampalis ${ }^{8} .{ }^{1}$ Schroeder Arthritis Institute, Rheumatology, Toronto, Canada;

${ }^{2}$ Laval University, Rheumatology, Quebec City, Canada; ${ }^{3}$ Southlake Regional Health Centre, Rheumatology, Newmarket, Canada; ${ }^{4}$ Nanaimo Regional General Hospital, Rheumatology, Nanaimo, Canada; ${ }^{5}$ Memorial University of Newfoundland, Rheumatology, New Foundland, Canada; ${ }^{6}$ Windsor Regional Hospital, Rheumatology, Windsor, Canada; ${ }^{7}$ Amgen Canada Inc., Global Medical Affairs, Mississauga, Canada; ${ }^{8}$ McGill University and JSS Medical Research, Epidemiology, Montreal, Canada 